\title{
La enfermedad hemorrágica viral del conejo impacta a México y amenaza al resto de Latinoamérica
}

A través de boletines emitidos por el Servicio Geológico de los Estados Unidos (USGS - United States Geological Survey) y el Departamento de Agricultura de Estados Unidos (USDA - United States Department of Agriculture), se confirmó el 13 de abril de 2020, la reaparición de la enfermedad hemorrágica viral del conejo (RHDV Rabbit Hemorrhagic Disease Virus) con la presencia del serotipo RHDV2 (Rabbit Hemorrhagic Disease Virus Serotype 2) en liebres (Lepus), conejos domésticos (Oryctolagus cuniculus) y silvestres (Sylvilagus, Romerolagus), incluso provocando alerta respecto a las pikas (Ochotona; Cima 2020). Hasta donde se conoce, esta enfermedad no es zoonótica, esto es, no se transmite de fauna silvestre a los humanos y tampoco tiene relación con el SARS-CoV-2, causante del COVID-19 u otro virus de afectación respiratoria en humanos. Las muertes de conejos (hasta 1,000 individuos) han ocurrido en varios condados de los estados de Arizona, California, Colorado, Nevada, Nuevo México y Texas en Estados Unidos. En México se reportaron eventos concurrentes de RHDV (no confirmados con pruebas de laboratorio) en la liebre de cola negra (Lepus californicus) y el conejo del desierto (Sylvilagus audubonii) en los municipios de Jiménez, Ahumada y Allende, en Chihuahua (Sleeman 2020). El 17 de abril, la Secretaría de Medio Ambiente y Recursos Naturales (SEMARNAT) confirmó la reaparición del RHDV. El llamado lo hizo a las Unidades de Manejo para la Conservación de la Vida Silvestre (UMAs) del país y pidió al público reportar al Servicio Nacional de Sanidad, Inocuidad y Calidad Agroalimentaria (SENASICA) la información necesaria en caso de detectar ejemplares sospechosos de tener la enfermedad.

A inicios de marzo de 2020, los autores (ALT y JAF) recibimos reportes de rancheros y propietarios de tierras en Sonora y Chihuahua el registro de muerte de conejos y liebres silvestres sin causa aparente. El 14 de marzo, The Arizona Game and Fish Department anunció que el RHDV2 había matado liebres y conejos silvestres en ese estado norteamericano. El pasado 3 de abril de 2020, se notificaron conejos domésticos muertos en un predio del municipio de Nuevo Casas Grandes, en Chihuahua, situación que fue atendida por SENASICA. La historia clínica de los conejos fue por muerte súbita y hemorragia nasal. El predio fue despoblado de otros conejos y desinfectado en su totalidad porque existía relación epidemiológica (SENASICA 2020a). SENASICA envió muestras de órganos de hígado y bazo de conejos domésticos al laboratorio de salud animal de la Comisión México-Estados Unidos certificado como nivel tres de bioseguridad. Posteriormente, se evaluaron también muestras similares de liebres y se confirmó la presencia de la enfermedad hemorrágica viral en estos organismos. Sin embargo, aún hace falta que se determine científicamente la identidad taxonómica a nivel de las especies silvestres afectadas en México.

Hasta el momento, conocemos que han sido afectados por el RHDV2: el conejo europeo doméstico (Oryctolagus cuniculus) hasta con 50 individuos muertos en granjas ubicadas en el norte de Chihuahua; además de las especies silvestres cuya identidad es necesario verificar (e. g., S. audubonii, S. floridanus y L. californicus) que han sido encontradas muertos en varios sitios del noreste y centro-sur de Durango, norte de Chihuahua, centro de Sonora, suroeste de Coahuila, norte de Baja California Sur y noroeste de Baja California (SENASICA 2020b; Figura 1; Tabla 1), donde se encontraron de 2 a 50 individuos muertos cada semana durante marzo. Hubo comunicación con las asociaciones locales de ganaderos para informarles sobre el manejo básico de los cadáveres y de la necesidad de notificar la situación a SENASICA.

La enfermedad hemorrágica viral del conejo. Es una enfermedad viral extremadamente contagiosa y a menudo mortal para los lagomorfos por el virus de la RHDV. La enfermedad es causada por un miembro del género Lagovirus y la familia Caliciviridae. El serotipo 2 o RHDV2 (identificado en Francia en 2010) tiene casi el 75-80 \% de letalidad en un periodo de dos a tres días en animales a partir de 10-15 días de edad. La muerte es el resultado de una disfunción circulatoria generalizada asociada con coagulación intravascular diseminada y lesiones de hepatitis necrotizantes, el hígado se considera el sitio prin-

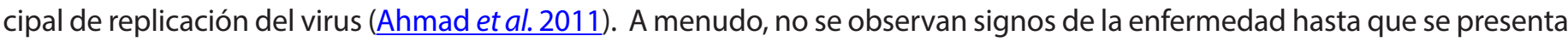
la muerte súbita y la nariz manchada de sangre, causada por una hemorragia interna asociada con necrosis hepática. Los lagomorfos infectados también pueden desarrollar fiebre, pierden el apetito, se muestran nerviosos o tienen respiración agitada, resultado de pulmones congestionados y edematosos (USDA y Animal and Plant Health Inspection Service 2019).

Aunque se desconoce el origen del RHDV, se cree que pudo haber surgido de calicivirus que circulan de forma asintomática en conejos europeos (O. cuniculus). El primer brote conocido de la enfermedad hemorrágica viral del conejo ocurrió en China en 1984, aparentemente propagado por conejos europeos, variedad angora, que habían sido importados de Europa (The Center for Food Security and Public Health et al. 2016). Posteriormente, se presentó en Corea en 1987 y se diseminó en Europa en 1988. El primer brote de RHDV reportado en el hemisferio occidental, ocurrió en México en 1988, 


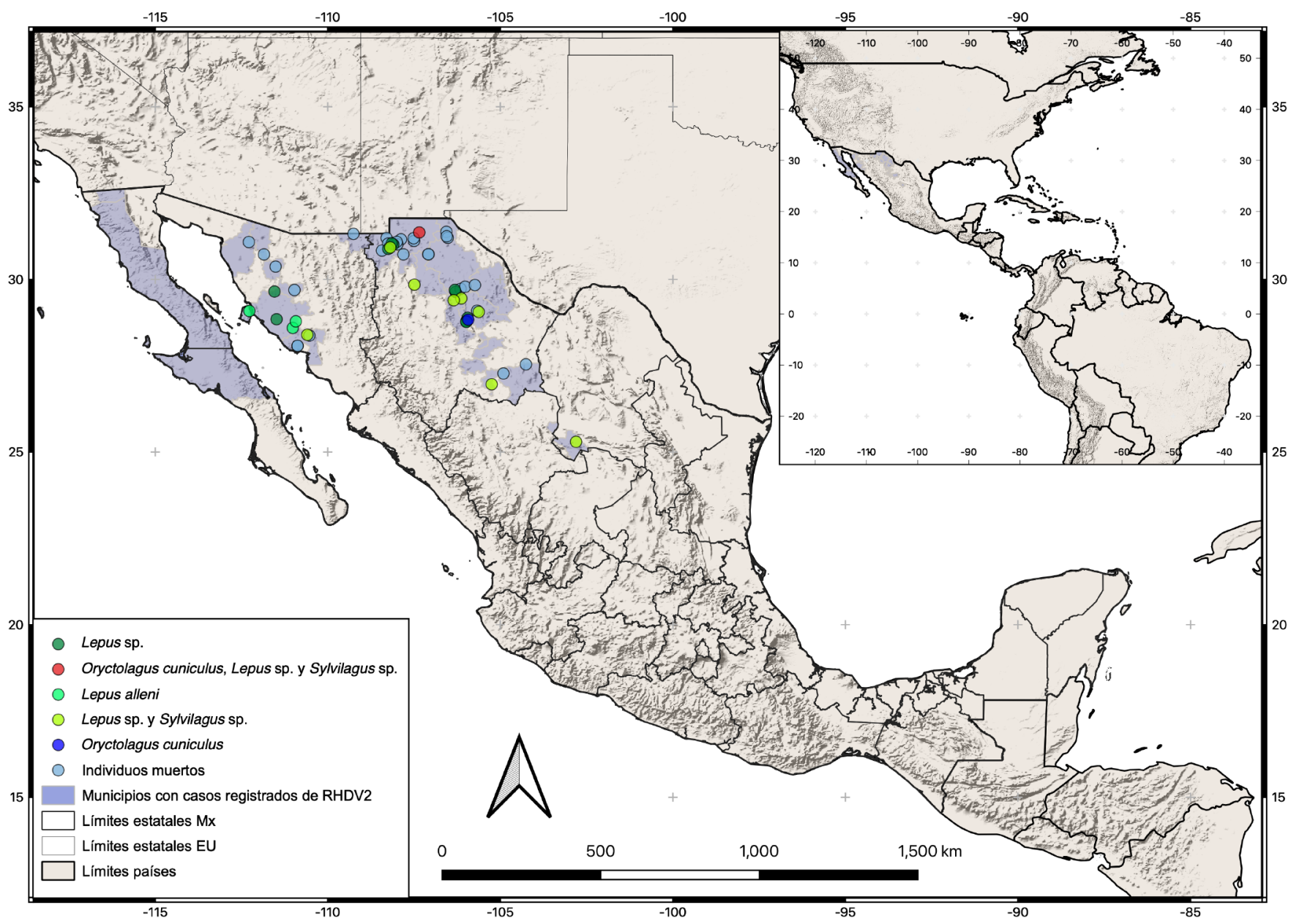

Figura 1. Registros de conejos domésticos y silvestres y liebres afectados por el RHDV2 en México. Se identifican las serranías en color gris obscuro.

provocado por la importación ilegal de canales de conejo originaria de China vía los Estados Unidos. La enfermedad se detectó en Cuba, en mayo de 1993 y en los Estados Unidos en abril de 2000, países que han sufrido reapariciones de la enfermedad en varias ocasiones (SENASICA 2020a). A inicios de este siglo, la enfermedad RHDV tuvo una distribución geográfica casi mundial (Mclntosh et al. 2007). Actualmente, se teme que la presencia del serotipo RDHV2 se pueda dispersar hacia el resto de Latinoamérica.

El virus RHDV2 es muy resistente a temperaturas extremas. Se puede transmitir a través de las canales de conejos domésticos destinadas al consumo humano, a través de contacto directo o por la exposición a las excreciones y secreciones o sangre de un conejo infectado. El virus también puede sobrevivir y propagarse a partir de cadáveres y su consumo por depredadores o carroñeros, al consumir alimentos, agua y cualquier material contaminado. Las personas pueden transmitir el virus indirectamente al portarlo en ropa y zapatos (USDA y Animal and Plant Health Inspection Service 2019).

Para evitar la propagación de la enfermedad se indica usar equipo de protección personal y descontaminar todo el equipo de campo, la ropa y los vehículos. Además, evitar las necropsias de campo y, en su lugar, se recomienda recoger los cadáveres por completo y transportarlos a un laboratorio de contención apropiado para realizarla. Los cadáveres que no sean sometidos a necropsia deben ser incinerados o enterrados profundamente para impedir el acceso de animales carroñeros y la contaminación ambiental, ya que el virus podría propagarse nuevamente por las moscas o en las heces de los depredadores (SENASICA 2020a).

\section{Importancia y efecto de la enfermedad hemorrágica viral del conejo en México,}

\section{Centroamérica y Sudamérica}

A medida que se acumularon casos reportados y basados en informes del suroeste de los Estados Unidos (Arizona, California, Colorado, Nevada, Nuevo México y Texas), surgieron preocupaciones sobre la salud de las granjas de conejos europeos y de ejemplares de razas exóticas mantenidas como mascotas, pero también acerca de las poblaciones de otros lagomorfos silvestres, debido a que el virus está afectando a las especies nativas. La presencia en el medio natural de las poblaciones de lagomorfos es básica, ya que, por su abundancia, son un elemento fundamental del delicado balance en las cadenas tróficas, tanto en su papel como consumidores primarios, así como de presas. Su desaparición parcial o total tendría consecuencias 
Tabla 1. Localidades donde se ha detectado la enfermedad hemorrágica viral del conejo en México. ${ }^{*}=$ Conejos domésticos y/o silvestres.

\begin{tabular}{|c|c|c|c|c|c|}
\hline Estado & Municipio & Sitio/Predio & Latitud & Longitud & Especies \\
\hline Baja California & Ensenada & No determinado & No determinada & No determinada & Conejos* \\
\hline Baja California & Ensenada & No determinado & No determinada & No determinada & Conejos* \\
\hline Baja California & Ensenada & No determinado & No determinada & No determinada & Conejos* \\
\hline Baja California & Ensenada & No determinado & No determinada & No determinada & Conejos* \\
\hline Baja California & Tecate & No determinado & No determinada & No determinada & Conejos* \\
\hline Baja California Sur & Mulegé & No determinado & No determinada & No determinada & Conejos* \\
\hline Chihuahua & Ascensión & Cerros Prietos & $30^{\circ} 43^{\prime} 49.9^{\prime \prime}$ & $107^{\circ} 05^{\prime} 02.2^{\prime \prime}$ & Individuos muertos \\
\hline Chihuahua & Ascensión & El Chamizo & $31^{\circ} 27^{\prime} 14.8^{\prime \prime}$ & $-107^{\circ} 31^{\prime} 28.8^{\prime \prime}$ & Individuos muertos \\
\hline Chihuahua & Ascensión & El Fresnal & $31^{\circ} 06^{\prime} 57.9^{\prime \prime}$ & $107^{\circ} 29^{\prime} 54.0^{\prime \prime}$ & Individuos muertos \\
\hline Chihuahua & Ascensión & Ejido Ascensión & $31^{\circ} 09^{\prime} 43.3^{\prime \prime}$ & $107^{\circ} 52^{\prime} 37.3^{\prime \prime}$ & Individuos muertos \\
\hline Chihuahua & Ascensión & Ejido Los Reyes & $31^{\circ} 03^{\prime} 15.6^{\prime \prime}$ & $108^{\circ} 08^{\prime} 23.0^{\prime \prime}$ & Individuos muertos \\
\hline Chihuahua & Ascensión & Laguna de Guzman & No determinada & No determinada & Individuos muertos \\
\hline Chihuahua & Ascensión & La Cruz & $31^{\circ} 01^{\prime} 00.2^{\prime \prime}$ & $108^{\circ} 06^{\prime} 03.6^{\prime \prime}$ & Lepus spp. \\
\hline Chihuahua & Ascensión & La Morita & $31^{\circ} 00^{\prime} 55.4^{\prime \prime}$ & $107^{\circ} 59^{\prime} 06.9^{\prime \prime}$ & Individuos muertos \\
\hline Chihuahua & Ascensión & Rancho Las Lilas & $30^{\circ} 55^{\prime} 39.0^{\prime \prime}$ & $108^{\circ} 11^{\prime} 22.9^{\prime \prime}$ & Lepus spp. y Sylvilagus spp. \\
\hline Chihuahua & Ascensión & Ranchos Tres Papalotes & $31^{\circ} 12^{\prime} 01.8^{\prime \prime}$ & $108^{\circ} 17^{\prime} 46.4^{\prime \prime}$ & Individuos muertos \\
\hline Chihuahua & Ascensión & Ranchos varios & $31^{\circ} 21^{\prime} 47.7^{\prime \prime}$ & $107^{\circ} 20^{\prime} 53.1^{\prime \prime}$ & Oryctolagus cuniculus, Lepus spp. y Sylvilagus spp. \\
\hline Chihuahua & Ascensión & Ranchos varios & $3105^{\prime} 26.0^{\prime \prime}$ & $108^{\circ} 00^{\prime} 04.0^{\prime \prime}$ & Individuos muertos \\
\hline Chihuahua & Aldama & Brecha Norte & $28^{\circ} 53^{\prime} 29.5^{\prime \prime}$ & $105^{\circ} 56^{\prime} 45.0^{\prime \prime}$ & Lepus spp. \\
\hline Chihuahua & Aldama & El Morrión & $29^{\circ} 03^{\prime} 37.0^{\prime \prime}$ & $105^{\circ} 37^{\prime} 24.7^{\prime \prime}$ & Lepus spp. y Sylvilagus spp. \\
\hline Chihuahua & Aldama & El Venado & $29^{\circ} 27^{\prime} 07.4^{\prime \prime}$ & $106^{\circ} 07^{\prime} 47.3^{\prime \prime}$ & Lepus spp. y Sylvilagus spp. \\
\hline Chihuahua & Aldama & La Mesa & $28^{\circ} 47^{\prime} 23.7^{\prime \prime}$ & $105^{\circ} 58^{\prime} 59.8^{\prime \prime}$ & Lepus spp. \\
\hline Chihuahua & Aldama & Molina & $28^{\circ} 46^{\prime} 19.0^{\prime \prime}$ & $105^{\circ} 58^{\prime} 59.8^{\prime \prime}$ & Lepus spp. \\
\hline Chihuahua & Aldama & Zoológico & $28^{\circ} 50^{\prime} 08.1^{\prime \prime}$ & $105^{\circ} 55^{\prime} 50.1^{\prime \prime}$ & Oryctolagus cuniculus \\
\hline Chihuahua & Chihuahua & El Coyamito & $29^{\circ} 43^{\prime} 40.8^{\prime \prime}$ & $106^{\circ} 09^{\prime} 02.9^{\prime \prime}$ & Individuos muertos \\
\hline Chihuahua & Chihuahua & El Faro & $29^{\circ} 23^{\prime} 49.5^{\prime \prime}$ & $106^{\circ} 20^{\prime} 58.3^{\prime \prime}$ & Lepus spp. y Sylvilagus spp. \\
\hline Chihuahua & Chihuahua & El Quince & $29^{\circ} 47^{\prime} 18.6^{\prime \prime}$ & $106^{\circ} 01^{\prime} 07.4^{\prime \prime}$ & Individuos muertos \\
\hline Chihuahua & Chihuahua & La Gregoria & $29^{\circ} 38^{\prime} 25.2^{\prime \prime}$ & $106^{\circ} 17^{\prime} 46.7^{\prime \prime}$ & Lepus spp. \\
\hline Chihuahua & Chihuahua & La India & $29^{\circ} 41^{\prime} 48.3^{\prime \prime}$ & $106^{\circ} 18^{\prime} 59.4^{\prime \prime}$ & Lepus spp. \\
\hline Chihuahua & Coyame & Gemelos & $29^{\circ} 05^{\prime} 40.2^{\prime \prime}$ & $105^{\circ} 40^{\prime} 15.8^{\prime \prime}$ & Individuos muertos \\
\hline Chihuahua & Coyame & Tres Castillos & $29^{\circ} 50^{\prime} 15.5^{\prime \prime}$ & $105^{\circ} 44^{\prime \prime} 10,5^{\prime \prime}$ & Individuos muertos \\
\hline Chihuahua & Janos & Camino a Buenavista & $31^{\circ} 02^{\prime} 12.5^{\prime \prime}$ & $108^{\circ} 15^{\prime} 01.7$ & Individuos muertos \\
\hline Chihuahua & Janos & El Uno & $30^{\circ} 50^{\prime} 16.5^{\prime \prime}$ & $108^{\circ} 25^{\prime} 38.2^{\prime \prime}$ & Individuos muertos \\
\hline Chihuahua & Janos & La Cruz & $31^{\circ} 02^{\prime} 36.1^{\prime \prime}$ & $108^{\circ} 08^{\prime} 43.5^{\prime \prime}$ & Lepus spp. \\
\hline Chihuahua & Janos & La Pradera & $30^{\circ} 53^{\prime} 13.3^{\prime \prime}$ & $108^{\circ} 14^{\prime} 39.4^{\prime \prime}$ & Lepus spp. \\
\hline Chihuahua & Jimenez & Huerta Nogalera & $27^{\circ} 16^{\prime} 39.4^{\prime \prime}$ & $104^{\circ} 54^{\prime} 35.0^{\prime \prime}$ & Individuos muertos \\
\hline Chihuahua & Jimenez & La Chavinda & $27^{\circ} 32^{\prime} 30.1^{\prime \prime}$ & $104^{\circ} 15^{\prime} 26.3^{\prime \prime}$ & Individuos muertos \\
\hline Chihuahua & Juárez & Ojo de En medio & $31^{\circ} 22^{\prime} 50.4^{\prime \prime}$ & $106^{\circ} 33^{\prime} 45.0^{\prime \prime}$ & Individuos muertos \\
\hline Chihuahua & Juárez & Rancho de Gonzalez & $31^{\circ} 12^{\prime} 24.6^{\prime \prime}$ & $106^{\circ} 31^{\prime} 23.4^{\prime \prime}$ & Individuos muertos \\
\hline Chihuahua & Juárez & Rancho Jose Corral & $31^{\circ} 15^{\prime} 05.7^{\prime \prime}$ & $106^{\circ} 33^{\prime} 12.4^{\prime \prime}$ & Individuos muertos \\
\hline Chihuahua & Meoqui & No determinado & No determinada & No determinada & Conejos* \\
\hline Chihuahua & Nuevo Casas Grandes & Palma Alta & $30^{\circ} 43^{\prime} 37.0^{\prime \prime}$ & $107^{\circ} 48^{\prime} 23.9^{\prime \prime}$ & Individuos muertos \\
\hline Chihuahua & San Buenaventura & Huertas & $29^{\circ} 50^{\prime} 54.4^{\prime \prime}$ & $107^{\circ} 29^{\prime} 17.6^{\prime \prime}$ & Lepus spp. y Sylvilagus spp. \\
\hline Chihuahua & Saucillo & No determinado & No determinada & No determinada & Conejos* \\
\hline Chihuahua & Valle de Allende & Varios Ranchos & $26^{\circ} 57^{\prime} 51.2^{\prime \prime}$ & $105^{\circ} 14^{\prime} 58.3^{\prime \prime}$ & Lepus spp. y Sylvilagus spp. \\
\hline Chihuahua & Valle de Zaragoza & No determinado & No determinada & No determinada & Conejos* \\
\hline Chihuahua & Villa Ahumada & Varios Ranchos & No determinada & No determinada & Lepus spp. y Sylvilagus spp. \\
\hline Coahuila & Viesca & La Viesca & $25^{\circ} 20^{\prime} 28^{\prime \prime}$ & $102^{\circ} 48^{\prime} 16^{\prime \prime}$ & Lepus spp. y Sylvilagus spp. \\
\hline
\end{tabular}


Continuación...

Tabla 1. Localidades donde se ha detectado la enfermedad hemorrágica viral del conejo en México. ${ }^{*}=$ Conejos domésticos y/o silvestres.

\begin{tabular}{llllll}
\hline \multicolumn{1}{c}{ Estado } & \multicolumn{1}{c}{ Municipio } & \multicolumn{1}{c}{ Sitio/Predio } & \multicolumn{1}{c}{ Latitud } & Longitud & Especies \\
\hline Durango & Gómez Palacio & No determinado & No determinada & No determinada & Conejos* \\
Durango & Delicias & No determinado & No determinada & No determinada & Conejos* \\
Sonora & Agua Prieta & San Bernardino & $31^{\circ} 19^{\prime} 18.5^{\prime \prime}$ & $109^{\circ} 15^{\prime} 18.5^{\prime \prime}$ & Individuos muertos \\
Sonora & Altar & Municipio & $30^{\circ} 43^{\prime} 33.0^{\prime \prime}$ & $111^{\circ} 50^{\prime} 54,2^{\prime \prime}$ & Individuos muertos \\
Sonora & Carbo & No determinado & $29^{\circ} 41^{\prime} 40.4^{\prime \prime}$ & $110^{\circ} 57^{\prime} 52.8^{\prime \prime}$ & Individuos muertos \\
Sonora & El Arivaipa & No determinado & $31^{\circ} 05^{\prime} 03.7^{\prime \prime}$ & $112^{\circ} 17^{\prime} 09.8^{\prime \prime}$ & Individuos muertos \\
Sonora & Félix Gomez & No determinado & $28^{\circ} 04^{\prime} 46.7^{\prime \prime}$ & $110^{\circ} 52^{\prime} 28.8^{\prime \prime}$ & Individuos muertos \\
Sonora & Guaymas & No determinado & $28^{\circ} 04^{\prime} 39.8^{\prime \prime}$ & $110^{\circ} 52^{\prime} 23.3^{\prime \prime}$ & Individuos muertos \\
Sonora & Guaymas & El Represo & $28^{\circ} 23^{\prime} 53.3^{\prime \prime}$ & $110^{\circ} 35^{\prime} 31.1^{\prime \prime}$ & Lepus spp.y Sylvilagus spp. \\
Sonora & Guaymas & La Pintada & $28^{\circ} 35^{\prime} 49.7^{\prime \prime}$ & $111^{\circ} 00^{\prime} 48.0^{\prime \prime}$ & Lepus alleni \\
Sonora & Hermosillo & La Mina & $28^{\circ} 47^{\prime} 15.8^{\prime \prime}$ & $110^{\circ} 55^{\prime} 30.5^{\prime \prime}$ & Lepus alleni \\
Sonora & La Misa & No determinado & $28^{\circ} 22^{\prime} 38^{\prime \prime}$ & $110^{\circ} 31^{\prime} 53^{\prime \prime}$ & Individuos muertos \\
Sonora & Miguel Alemán & Rancho Escalante & $28^{\circ} 50^{\prime} 58.11^{\prime \prime}$ & $111^{\circ} 28^{\prime} 57.6^{\prime \prime}$ & Lepus spp. \\
Sonora & Región & No determinado & $29^{\circ} 39^{\prime} 02.2^{\prime \prime}$ & $111^{\circ} 32^{\prime} 34.7^{\prime \prime}$ & Lepus spp. \\
Sonora & Trincheras & La Esperanza & $30^{\circ} 22^{\prime} 19.2^{\prime \prime}$ & $111^{\circ} 30^{\prime} 36.6^{\prime \prime}$ & Individuos muertos \\
Sonora & Isla Tiburón & Zona noroeste & $29^{\circ} 05^{\prime} 48.7^{\prime \prime}$ & $112^{\circ} 16^{\prime} 18.8^{\prime \prime}$ & Lepus alleni \\
\hline
\end{tabular}

de alcances inimaginados en los procesos ecológicos de los ecosistemas, seguramente con impactos negativos muy importantes en las poblaciones de las especies que se alimentan de lagomorfos y por tanto dependen de ellas, como serpientes de cascabel (Crotalus spp.), gatos monteses (Lyns rufus), coyotes (Canis latrans) y diversas especies de aves de presa (Lorenzo et al. 2015), con efectos en cascada difíciles de anticipar.

Existen 63 especies de lagomorfos lepóridos en el mundo (Smith et al. 2018) y México es uno de los países con mayor riqueza, debido a que está compuesta por 14 especies: 9 conejos (8 del género Sylvilagus y 1 del género Romerolagus) y 5 liebres (del género Lepus). La preocupación por la presencia del RHDV2 crece por la afectación que puedan presentar sus poblaciones; principalmente aquellas especies vulnerables o en peligro de extinción, así como aquellas que presentan áreas de distribución restringida o se distribuyen en áreas de importancia para la biodiversidad. Por ejemplo, el conejo zacatuche (Romerolagus diazi) en el Eje Neovolcánico es de particular preocupación porque el gobierno mexicano lo enlista en peligro de extinción (Trujillo-Segura 2019) y la International Union for the Conservation of Nature (IUCN) lo clasifica en peligro (Velázquez y Guerrero 2019). Otro ejemplo relevante se ubica en el norte de México (Coahuila), donde puede encontrarse el conejo de las montañas Davis, S. robustus, el cual es vulnerable según la IUCN (Ruedas y Smith 2019). Por otra parte, en los desiertos de Chihuahua y Sonora se distribuye la liebre de costados blancos (Lepus callotis), clasificada como vulnerable (Brown y Smith 2019) y la liebre antílope (Lepus alleni), considerada en la categoría de preocupación menor (Lorenzo y Brown 2019).

En el escenario hipotético de que el brote epidémico del RHDV2 se desbordara de manera natural a otras especies de lagomorfos silvestres distribuidas en el centro y sur de México y sin considerar la posible transportación de conejos domésticos a otras regiones ni el desplazamiento humano, su efecto sería devastador, provocando una pérdida de grandes dimensiones en la diversidad de especies de lagomorfos por tratarse de un virus altamente infeccioso y resistente a cambios ambientales. El RHDV2 requiere infectar un hospedero natural para su supervivencia, por lo que la distribución de las especies podría indicar las posibles rutas de dispersión del virus, sobre todo aquellas en las que no existen barreras geográficas que eviten su paso.

Debido a lo anterior, consideramos que las posibles vías de dispersión del RHDV2 en México pueden ser la parte norte de las planicies costeras en sus vertientes Pacífico y Golfo, así como la Meseta Central de México (Figura 1). A través de la Planicie Costera del Pacífico se verían afectadas poblaciones de los conejos, S. audubonii, S. floridanus y S. cunicularius (al noroeste de su distribución) y las liebres L. californicus (en el extremo norte) y L. alleni. En la Planicie Costera del Golfo, afectaría a los conejos, S. floridanus y S. gabbi (en el extremo norte) y a las liebres, L. californicus y L. altamirae (en el extremo norte; $\underline{\text { Vargas }}$ et al. 2019). En la Meseta Central se verían afectadas poblaciones de los conejos S. floridanus, S. audubonii y S. robustus y las liebres L. californicus y L. callotis. El avance del virus podría ser más lento para alcanzar a las especies serranas y aisladas, como R. diazi y S. insonus (en Sierra Madre del Sur de Guerrero). En cuanto a la Península de Baja California, el Río Colorado y Sierra de Juárez al norte de Baja California, son una fuerte barrera para el paso del RHDV2 proveniente del continente en territorio mexicano. Sin embargo, puede llegar por el norte desde el estado de California en los Estados Unidos, en este caso las especies que pueden verse afectadas son los conejos S. audubonii, S. bachmani y la liebre L. californicus. La dispersión natural del virus hacia las especies y subespecies de lagomorfos silvestres que habitan en las islas del Golfo de California 
(S. bachmani mansuetus, Isla San José; L. alleni tiburonensis, Isla Tiburón; L. C. sheldoni, Isla Carmen; L. c. insularis, Isla Espíritu Santo; L. c. xanti, Isla Cerralvo) y del Océano Pacífico mexicano (S. graysoni, Islas Marías; L. c. magdalenae, Islas Magdalena y Margarita), se esperaría que fuera muy baja debido a su aislamiento geográfico. Sin embargo, el contagio podría facilitarse por el transporte involuntario a través de la ropa y calzado de las personas, o por medio de depredadores como aves de presa, como se piensa que pudo haber ocurrido en la Isla Tiburón en abril y mayo de 2020.

En Guatemala existen sistemas montañosos que se extienden hacia la frontera con México (Chiapas) como la Altiplanicie Central (Macizo Central o Los Altos de Chiapas), que se desplaza por la parte central del estado y proviene de Guatemala (Sierra de los Cuchumatanes) o la Franja Volcánica que inicia cerca de la frontera con Chiapas por la vertiente del Pacífico y se extiende por el centro del país. Estas barreras, junto con el cierre del Istmo Centroamericano (hace 2 a 5 millones de años aproximadamente) fueron de gran importancia para filtrar la dispersión de varias especies de lagomorfos de norte a sur, como son las liebres cuyo límite de distribución sureña es el Istmo de Tehuantepec (con L. flavigularis) y, por tanto, no se encuentran en Centroamérica y Sudamérica. Sin embargo, algunos conejos pudieron migrar hacia al sur y son éstos los que podrían verse afectados por el RHDV2, como S. brasiliensis, que se encuentra hasta el norte de Argentina, S. gabbi hasta Colombia y $S$. floridanus hasta Colombia y Venezuela. Otras poblaciones de conejos llegaron a especiar y actualmente son endémicos y con distribución local en algunos países, S. dicei en Costa Rica, S. andinus en Perú, S. varynaensis en Venezuela y S. tapetillus en Brasil; son éstos los que pueden ser un foco de atención ante eventos de posibles brotes del RHDV2.

\section{Exhorto}

Consideramos que las líneas de investigación futuras que deben tomarse en cuenta para evitar en la medida de lo posible brotes del RHDV2 deben enfocarse en contener el paso del virus, evitando (como se ha hecho) la restricción de transportar conejos domésticos a otras regiones, para lo cual se requiere contar con datos y rutas sobre la importación, cría, o ambos, del conejo doméstico en diferentes países, con el fin de tener una idea del riesgo sanitario de introducción. Es de importancia evaluar la riqueza de los lepóridos en Latinoamérica para identificar zonas que podrían ser de alta preocupación y atención inmediata. Así como colaborar con diferentes sectores sociales y académicos nacionales y extranjeros para contar con registros precisos de fechas de aparición de brotes y llevar al cabo acciones conjuntas para su manejo y para evitar su dispersión.

Aunque en México existen programas de erradicación de RHDV en conejos domésticos desde 1989 por parte del Sistema Nacional de Emergencia en Salud Animal (SINESA), se requiere de información detallada recopilada en campo para evaluar variaciones en el tamaño de las poblaciones silvestres infectadas con el virus RHDV2. Por todo lo anterior, es fundamental la cooperación entre las autoridades gubernamentales, el sector académico y los habitantes locales para realizar trabajo de campo coordinado para implementar medidas de bioseguridad con el fin de contener la RHDV2 en poblaciones silvestres, ya que la propagación indirecta del virus es altamente efectiva.

Existen vacunas para RHDV2 para conejos domésticos; sin embargo, no están aprobadas para uso comercial en los Estados Unidos. Además, existe una protección cruzada limitada o nula entre los grupos de virus, es decir, que se debe elegir el tipo de vacuna de acuerdo con la variante de la que se busque inducir una reacción inmunogénica (SENASICA 2020a). No existen vacunas para las especies silvestres y si así fuera, su aplicación requeriría de un gran esfuerzo ya que los animales tendrían que atraparse, vacunarse y liberarse. Como en pasados eventos de pandemia de la enfermedad hemorrágica viral del conejo, es probable que, a partir de los sobrevivientes inmunes, se pueda obtener una inmunidad de la población después de un tiempo. Sin embargo, es necesario unir esfuerzos para enfrentar este reto que enfrenta la conservación y aprovechamiento sustentable de la biodiversidad y mitigar sus efectos que, finalmente sumado a otros eventos similares, incide sobre la supervivencia de la especie humana.

Consuelo Lorenzo ${ }^{1 *}$, Alberto Lafón-Terrazas ${ }^{2}$, Jesús A. Fernández ${ }^{3}$, Fernando A. Cervantes ${ }^{4}$, y Enrique Martínez-Meyer ${ }^{5}$

*Corresponding author

\footnotetext{
${ }^{1}$ Departamento de Conservación de la Biodiversidad, El Colegio de la Frontera Sur. Carretera Panamericana y Periférico Sur s/n, Barrio María Auxiliadora, CP. 29290, San Cristóbal de Las Casas, Chiapas, México. Email: clorenzo@ecosur.mx (CL).

${ }^{2}$ Protección de la Fauna Mexicana, A. C. Calle 16 2604, Chihuahua, Chihuahua, México. Email: gruscan@yahoo.com.mx (AL-T).

${ }^{3}$ Departamento de Recursos Naturales, Facultad de Zootecnia y Ecología, Universidad Autónoma de Chihuahua, Periférico Francisco R. Almada Km. 1, CP. 31453, Chihuahua, México. Email: afernandezf@uach.mx (JAF).

${ }^{4}$ Colección Nacional de Mamíferos, Departamento de Zoología, Instituto de Biología, Universidad Nacional Autónoma de México. Ciudad Universitaria, CP. 04510, Ciudad de México, México, y Asociación Mexicana para la Conservación y Estudio de los Lagomorfos, A. C., CP. 04960, Ciudad de México, México. Email: fac@ib.unam.mx (FAC).

${ }^{5}$ Departamento de Zoología, Instituto de Biología, Universidad Nacional Autónoma de México. Ciudad Universitaria, CP. 04510, Ciudad de México, México. Email: emm@ib.unam.mx (EM-M).
} 


\section{Literatura citada}

Ahmad, S. T., H. A. El-samadony, y K. M. Mahgoub. 2011. Immunological and Virological Studies on Rabbit Hemorrhagic Disease Virus. Global Veterinaria 7:545-556.

Brown, D. E., y A. T. Smith. 2019. Lepus callotis. The IUCN Red List of Threatened Species 2019: e.T11792A45177499. DOI:10.2305/IUCN.UK.2019-2.RLTS.T11792A45177499.en. Consultado el 24 de Junio de 2020.

CIMA, G. 2020. Rabbit hemorrhagic disease virus serotype 2 spreading among wild rabbits, hares. JAVMA News. https:// www.avma.org/javma-news/2020-07-15/virus-killingrabbits-western-us. Consultado el 20 de junio de 2020.

Lorenzo, C., T. M. Rıoja-Paradela, y A. Carrillo-Reyes. 2015. State of knowledge and conservation of endangered and critically endangered lagomorphs worldwide. Therya 6:11-30.

Lorenzo, C., y D.E. Brown. 2019. Lepus alleni. The IUCNRed List of Threatened Species 2019: e.T41272A45185265. DOI:10.2305/ IUCN.UK.2019-1.RLTS.T41272A45185265.en. Consultado el 24 de junio de 2020.

McIntosh, M. T., S. C. Behan., F. M. Mohamed, Z. Lu, K. E. Moran, T. G. Burrage, J. G. Neilan, G. B. Ward, G. Bottı, L. Capuccl, y S. A. Metwally. 2007. A pandemic strain of calicivirus threatens rabbit industries in the Americas. Virology Journal 4:96.

Ruedas, L. A., y A. T. Smith. 2019. Sylvilagus robustus (errata version published in 2020). The IUCN Red List of Threatened Species 2019: e.T41310A165116781. DOI:10.2305/IUCN. UK.2019-3.RLTS.T41310A165116781.en. Consultado el 24 de junio de 2020.

Servicio Nacional de Sanidad, Inocuidad y Calidad Agroalimentaria (SENASICA). 2020a. Informe de Inteligencia Epidemiológica de la Enfermedad Hemorrágica Viral del Conejo. Análisis Estratégico de Riesgos Sanitarios.

Servicio Nacional de Sanidad, Inocuidad y Calidad Agroalimentaria (SENASICA). 2020b. Seguimiento epidemiológico No. 8 de los focos de la Enfermedad Hemorrágica de los conejos en México, 2020.

Sleeman, J. 2020. Continued Expansion of Rabbit Hemorrhagic Disease Virus 2 in North America and Additional Instructions Regarding Mortality Event Investigations. USGS National Wildlife Health Center. Wildlife Health Bulletin 2020-05. https://www.usgs.gov/centers/nwhc/science/diseaseinvestigation-services Consultado el 24 de junio de 2020

Smith, A. T., C. H. Johnston, P. C. Alves, y K. Häcklander. 2018. Lagomorphs. Pikas, Rabbits and Hares of the World. John Hopkins University Press. Baltimore, EE.UU.

The Center for Food Security \& Public Health, Institute for International Cooperation in Animal Biologics, lowa State University, World Organization for Animal Health (OlE), y United States Department of Agriculture (USDA). 2016. Rabbit Hemorrhagic Disease. Viral Hemorrhagic Disease of Rabbits, Rabbit Calicivirus Disease. http://www.cfsph.iastate. edu/Factsheets/pdfs/rabbit hemorrhagic disease.pdf. Consultado el 25 de junio de 2020.

Trujillo-Segura, J. C. J. 2019. MODifiCACIÓN del Anexo Normativo III, Lista de especies en riesgo de la Norma Oficial Mexicana NOM-059-SEMARNAT-2010, Protección ambientalEspecies nativas de México de flora y fauna silvestresCategorías de riesgo y especificaciones para su inclusión, exclusión o cambio-Lista de especies en riesgo, publicada el
30 de diciembre de 2010. Diario Oficial de la Federación 14 de noviembre de 2019.

United States Department of Agriculture (USDA), y Animal and Plant Health Inspection Service. 2019. Factsheet. Rabbit Hemorrhagic Disease. vs.ceah@usda.gov. Consultado el 25 de junio de 2020.

Vargas, K., D. Brown, E. Wisely, y M. Culver. 2019. Reinstatement of the Tamaulipas white-sided jackrabbit, Lepus altamirae, based on DNA sequence data. Revista Mexicana de Biodiversidad 90:e902520.

Velázquez, A., y J. A. Guerrero. 2019. Romerolagus diazi. The IUCN Red List of Threatened Species 2019: e.T19742A45180356. DOI:10.2305/IUCN.UK.2019-2.RLTS. T19742A45180356.en. Consultado el 24 de Junio de 2020. 